\title{
Telehealth Psychotherapy for Severe Personality Disorder during COVID-19: Experience of Australian Clinicians
}

\author{
Jillian H Broadbear ${ }^{1,2}$, Parvaneh Heidari ${ }^{1,2}$, Nitin P Dharwadkar ${ }^{3}$, Lukas Cheney ${ }^{1}$ \& Sathya Rao ${ }^{1,2}$ \\ ${ }^{1}$ Spectrum Service for Personality Disorder, Richmond, Victoria, Australia \\ ${ }^{2}$ Faculty of Medicine, Nursing and Health Sciences, Monash University, Clayton, Victoria, Australia \\ ${ }^{3}$ Department of Psychiatry, Central Clinical School, Monash University, Melbourne, Victoria, Australia \\ Correspondence: A/Prof Jillian Broadbear, Spectrum Personality Disorder Service, Level 1, 110 Church St, \\ Richmond, Victoria, 3121, Australia. Tel: 613-8413-8750.
}

Received: September 22, 2021 Accepted: October 18, 2021 Online Published: November 5, 2021

doi:10.5539/gjhs.v13n12p61 URL: https://doi.org/10.5539/gjhs.v13n12p61

\begin{abstract}
Objective: Restrictions on social interaction during the COVID-19 pandemic necessitated a rapid transition to telehealth to continue providing psychotherapy to people diagnosed with personality disorder. This naturalistic cross-sectional study evaluated the experiences of clinicians using telehealth for the first time to treat clients diagnosed with a severe personality disorder (complex and/or high risk presentation).

Methods: Thirty clinicians working at a specialist clinic for personality disorders completed an online survey during May-June 2020 in Melbourne, Australia.

Results: Despite having some initial technical issues, most participants rapidly and successfully connected with clients via phone and/or video-conference, recommencing individual and group evidence-based psychotherapies. Appointments were kept more reliably than when in-person treatment was offered. Issues around privacy, confidentiality, risk, quality of interaction, and treatment boundaries were raised, highlighting the need for specific guidelines and formal processes. However, clinicians' awareness of some of the benefits of telehealth was evident, with most looking forward to using telehealth for some aspects of their work with clients and more generally into the future.

Conclusions: This experience with delivering psychotherapy using telehealth during COVID restrictions suggests that it is an acceptable platform that can be managed safely for treating patients with severe mental illness in the short term at least. This outcome encourages the pursuit of efficacy studies to evaluate telehealth as a more equitable and accessible treatment modality.
\end{abstract}

Keywords: telemedicine, telemental health, personality disorder, borderline personality disorder, COVID-19

\section{Introduction}

On March 11, 2020, the World Health Organization (WHO) declared Coronavirus Disease 2019 (COVID-19) a pandemic, recommending containment efforts such as social distancing and home isolation. Like many other countries, Australia adopted workplace and community restrictions to limit the spread of the virus ("Government response to the COVID-19 outbreak," 2020). Workplace attendance was strictly limited; in-person healthcare services were replaced wherever possible with telehealth services to maintain continuity of care (Looi \& Pring, 2020).

The WHO defines telehealth as the delivery of healthcare services via information and communications technology (World Health Organisation, 2020). Telehealth was previously identified as a realistic and viable approach for improving and expanding mental health services prior to the pandemic (Kocsis \& Yellowlees, 2018; Perle \& Nierenberg, 2013) to children, adolescents, and adults (Luo et al., 2020; Osenbach, O'Brien, Mishkind, \& Smolenski, 2013). Psychotherapy for depression has been the most widely investigated, with most studies reporting a reduction in depressive symptoms using treatments such as Cognitive Behavioral Therapy delivered via telephone (Mohr, Vella, Hart, Heckman, \& Simon, 2008) or more recently via video platforms (Berryhill et al., 2019). Despite substantial methodological differences among these studies, meta-analyses suggest some equivalence between video-telehealth and in-person sessions in the treatment of depressive symptoms (Berryhill et 
al., 2019; Luo et al., 2020).

Prior to COVID, some studies reported reluctance among patients and clinicians to receive and provide treatment via telehealth platforms. Several pre-pandemic studies prospectively explored attitudes towards telehealth psychiatric services. One that focused on rural and urban primary healthcare patients $(n=190)$ found that over one-third were moderately or highly comfortable with the thought of using telehealth from home. This increased to $45 \%$ if using telehealth would save them a two-hour drive (Grubaugh, Cain, Elhai, Patrick, \& Frueh, 2008). However, more than $60 \%$ of participants anticipated that tele-psychiatry would not be as helpful as in-person sessions (Grubaugh et al., 2008), a perception shared by many clinicians (Lopez, Schwenk, Schneck, Griffin, \& Mishkind, 2019). A survey of telehealth use by people diagnosed with severe personality disorder was conducted during the early stages of the COVID-19 pandemic. Despite some early challenges during the transition to receiving psychotherapy via telehealth, telehealth played an important role in maintaining continuity of care, with half those surveyed wanting the option of telehealth in the future (Dharwadkar, Broadbear, Heidari, Cheney, \& Rao, under review).

A recent teletherapy review observed that studies to date have generally restricted recruitment to patients with less severe symptomology (Markowitz et al., 2020), limiting our ability to generalize to more severely unwell patients. Personality disorder, with a global prevalence of approximately six percent, is a severe and complex mental disorder associated with high utilization of healthcare services (Huang et al., 2009; Leichsenring, Leibing, Kruse, New, \& Leweke, 2011). Personality disorders can lead to significant problems in engaging effectively in relationships, education, and employment. Evidence-based treatments have been established for some personality disorders, particularly borderline personality disorder (BPD), predicated on in-person psychotherapy (Budge et al., 2013). The literature is silent regarding the efficacy or acceptability of telehealth for treating patients diagnosed with BPD, which frequently involves severe, complex, and high-risk presentations that include self-injury and chronic suicidality (Broadbear, Dwyer, Bugeja, \& Rao, 2020). This study complements a companion study of clients' perspectives (Dharwadkar et al., under review) by investigating the experiences of clinicians who provided telehealth psychotherapy to patients diagnosed with severe and complex personality disorder. The aim of the present study was to explore clinician preconceptions, benefits, shortcomings, and future use of telehealth for providing psychotherapy to clients diagnosed with personality disorder.

\section{Methods}

A cross-sectional study was conducted using an online survey of clinicians employed by a specialist personality disorder clinic during the initial COVID-19 lockdown (May-June 2020). This format was chosen to reach participants during lockdown and ensure anonymity of their responses. The clinic provides care for people diagnosed with moderate to severe personality disorder; borderline personality disorder in most instances. Clients of the service usually have co-occurring mental health disorders and involvement with multiple health service providers. The clinic provides evidence-based psychotherapy treatments including Mentalisation Based Therapy, Dialectical Behavioral Therapy, a 'Common Factors' treatment program, and Psychoanalytic Therapy. All clinicians employed in the clinic were invited to participate via email, informing them of the purpose of the study, providing a link to the survey, describing the voluntary nature of the study, and the anonymity of participant responses. Informal (verbal and written) feedback was obtained eight months after the initial survey at a staff meeting to assess further developments in their experience of providing psychotherapy via telehealth.

The online survey developed for this study contained multiple-choice and open-ended questions which asked clinicians about the telehealth platform that they used (video-conference, phone, or mixed), their prior experience with telehealth, challenges experienced during their transition to telehealth, and their positive and negative perceptions of using telehealth for providing psychotherapeutic treatment to clients diagnosed with personality disorder. They were also asked to reflect on clinical benefits associated with delivering treatment remotely as well as the desirability of having the telehealth option for treatment delivery in the future.

Quantitative data from the multiple-choice questions were reported descriptively; qualitative data from the open-ended questions were examined using inductive content analysis (Elo \& Kyngäs, 2008; Fife, 2020). Two of the authors independently coded these data, identifying common themes by consensus. Quotations were used to illustrate the findings. The study was conducted in accordance with the Declaration of Helsinki and National Statement on Ethical Conduct in Human Research and was approved by the institutional ethics committee (LR20/037).

\section{Results}

Thirty surveys were completed ( $86 \%$ response rate). Participants were aged between 28 and 64 years; most were 
female ( $\mathrm{n}=21,70 \%)$. With respect to telehealth platforms, the majority used a mix of video-conference and phone according to client preference $(n=19 ; 63.3 \%)$ and internet connection quality $(n=11 ; 36.6 \%)$.

\subsection{Experience of Telehealth Prior to the Pandemic}

Eleven participants $(36.6 \%)$ had prior experience with telehealth for activities including remote clinical supervision, secondary consultation, telephone consultation, assessment, client coaching, or case conferences. None had used telehealth previously for administering evidence-based psychotherapy to clients.

Prior to COVID-19, 23 participants (76.6\%) reported having doubts regarding the use of telehealth in clinical work, expressing concerns about security, confidentiality, privacy; their lack of familiarity with telehealth platforms; the adequacy of telehealth for providing quality clinical support; challenges building a therapeutic relationship with a client, and difficulty assessing client risk and safety.

'Concerns about security and privacy of telehealth platforms, and the ability to engage meaningfully and provide the same quality of service via telehealth as can be provided [in-person], especially for new clients'P2

Nineteen participants $(63.3 \%)$ cited service/employer-based constraints on the use of telehealth prior to the pandemic, specifically a lack of expectation and guidance regarding the delivery of psychotherapy via telehealth, lack of infrastructure and software support, limited client access to the reciprocal equipment and software, and the sense that the service was 'anti-telehealth'. There was skepticism about the efficacy of using telehealth, with in-person psychotherapy regarded as the 'gold standard'. A few noted potential advantages of telehealth, including convenience and equity of access to services.

\section{'Lack of Ability to Connect With Clients, Manage Risk' P26}

\subsection{Transition to telehealth}

Many participants described their transition to telehealth as 'Mostly straightforward but with a few teething problems' (58.6\%). Ten had technical issues while transitioning that were resolved quickly (34.4\%). Two (6.9\%) were still having problems that prevented them from successfully engaging with clients using telehealth. Specific challenges regarding the transition to and use of telehealth experienced by clinician participants and their clients are listed in Tables 1 and 2 .

'The sudden transition gave little time to prepare or think about it. Mostly straight forward and no major technological issues, however working offsite, there seemed to be extra steps ... that were more time consuming than working in the office.' P6

Table 1 . Challenges the transition to telehealth presented to clinicians in a personality disorder clinic $(n=29)$

\begin{tabular}{|c|c|c|c|}
\hline $\begin{array}{l}\text { Challenge } \\
\text { type }\end{array}$ & Nature of challenge & Specific issue & n (\%) \\
\hline \multirow{7}{*}{ Contextual } & \multirow{4}{*}{ Technical issues } & Inadequate access to internet equipment & $5(17.2)$ \\
\hline & & $\begin{array}{l}\text { Ensuring adequate technology capabilities/ Ensuring that } \\
\text { technical facilities are working }\end{array}$ & $5(17.2)$ \\
\hline & & Difficulty accessing client files remotely & $3(10.3)$ \\
\hline & & Unstable internet access & $4(13.7)$ \\
\hline & \multirow{2}{*}{ Clinician Workplace Safety } & Appropriateness of home work space & $3(10.3)$ \\
\hline & & Fatigue working with telehealth & $3(10.3)$ \\
\hline & Privacy & $\begin{array}{l}\text { Finding a quiet, private space (concerns regarding home } \\
\text { settings and the security of telehealth for confidential } \\
\text { conversations) }\end{array}$ & $9(31.0)$ \\
\hline \multirow{3}{*}{ Individual } & \multirow{3}{*}{ Coping with change } & Resistance to/suddenness of change & $3(10.3)$ \\
\hline & & Higher anxiety before a session & $1(3.4)$ \\
\hline & & Loss of supportive contact with colleagues & $2(6.8)$ \\
\hline Clinical & Therapeutic relationship & $\begin{array}{l}\text { Concerns regarding development and maintenance of the } \\
\text { therapeutic relationship, particularly when working with an } \\
\text { existing problem or engaging with a new client }\end{array}$ & $5(17.2)$ \\
\hline
\end{tabular}




\begin{tabular}{lll} 
Risk management & Ascertaining and appropriately responding to risk & $1(3.4)$ \\
\hline \multirow{2}{*}{ Assessment and Treatment } & Reduced quality of engagement via telehealth & $1(3.4)$ \\
\cline { 2 - 3 } & Difficulties observicing and interpreting non-verbal cues & $5(17.2)$ \\
\cline { 2 - 3 } & General engagement difficulties/deficiencies & $5(17.2)$ \\
\hline \multirow{2}{*}{ Maintaining boundaries } & $\begin{array}{l}\text { Difficulty in maintaining boundaries and work structure } \\
\text { when working from home }\end{array}$ & $6(20.6)$
\end{tabular}

I have focused more on rapport because it feels that this is harder to achieve via telehalth. This has meant taking longer to complete treatment plan.' $\mathrm{P} 26$

Table 2. Clinicians' perspective on challenges the transition to telehealth presented to clients with personality disorder $(\mathrm{n}=27)$

\begin{tabular}{|c|c|c|c|}
\hline $\begin{array}{l}\text { Challenge } \\
\text { type }\end{array}$ & Nature of challenge & Specific issue & n (\%) \\
\hline \multirow{6}{*}{ Contextual } & \multirow{3}{*}{ Technical issues } & Technical issues; teaching clients how to use it & $2(7.4)$ \\
\hline & & Unstable internet & $9(33.3)$ \\
\hline & & Telehealth platform does not support group sessions & $2(7.4)$ \\
\hline & \multirow{2}{*}{ Access to equipment } & Access to equipment & $9(33.3)$ \\
\hline & & Financial difficulty providing equipment and internet & $1(3.7)$ \\
\hline & Privacy & $\begin{array}{l}\text { Finding a quiet, private space (concerns regarding shared spaces } \\
\text { and the security of telehealth) }\end{array}$ & $9(33.3)$ \\
\hline \multirow{8}{*}{ Individual } & \multirow[b]{2}{*}{ Client preference } & Some clients refused video and opted for phone & $3(11.1)$ \\
\hline & & $\begin{array}{l}\text { Some clients liked the convenience of telehealth; difficult topics } \\
\text { easier to discuss }\end{array}$ & $4(14.8)$ \\
\hline & Sense of isolation & Lack of contact with people more generally as well as the therapist & $3(11.1)$ \\
\hline & Communication & Difficult to build a rapport via telehealth & $4(14.8)$ \\
\hline & \multirow{2}{*}{ Lack of structure } & Lack of structure around attending the session & $2(7.4)$ \\
\hline & & Less (quality of) engagement via telehealth & $7(25.9)$ \\
\hline & \multirow{2}{*}{$\begin{array}{l}\text { Effect on client } \\
\text { presentation }\end{array}$} & Paranoia aroused, more of a struggle, destabilizing & $5(18.5)$ \\
\hline & & Initial apprehension & $4(14.8)$ \\
\hline
\end{tabular}

\subsection{Clinical Characteristics of Telehealth in Delivering Psychotherapy}

Participants were asked about the changes in the way they delivered psychotherapy via telehealth. Table 3 summarises their responses. 
Table 3. Changes in the delivery and quality of psychotherapy sessions via telehealth relative to in-person sessions

\begin{tabular}{|c|c|c|c|}
\hline \multirow[t]{2}{*}{ Parameter } & \multicolumn{2}{|c|}{$\begin{array}{l}\text { Was there any change? } \\
\text { n (\%) }\end{array}$} & \multirow[t]{2}{*}{ Direction of change, $n(\%)$} \\
\hline & Yes & No & \\
\hline \multirow{2}{*}{ Session duration, $\mathrm{n}=29$} & \multirow{2}{*}{$13(44.8)$} & \multirow{2}{*}{$16(55.1)$} & Shorter, 8 (61.5) \\
\hline & & & Longer, 5 (38.5) \\
\hline \multirow{2}{*}{ Session punctuality, $\mathrm{n}=29$} & \multirow{2}{*}{$15(51.7)$} & \multirow{2}{*}{$14(48.2)$} & Less punctual, 13 (84.6); mostly due to technical issues \\
\hline & & & More punctual, 2 (15.3) \\
\hline \multirow{3}{*}{$\begin{array}{l}\text { The nature of what is } \\
\text { discussed/disclosed, } n=28\end{array}$} & \multirow{3}{*}{$16(57.1)$} & \multirow{3}{*}{$12(42.8)$} & Less content is disclosed and discussed, 9 (56.3) \\
\hline & & & More content is disclosed and discussed, 5 (31.3) \\
\hline & & & Varies among clients, 2 (12.5) \\
\hline $\begin{array}{l}\text { Ability to stay focused/engaged (you } \\
\text { and/or your client) }, n=29\end{array}$ & $20(68.9)$ & $9(31.0)$ & More difficult to stay engaged and focused, 20 (100) \\
\hline \multirow{3}{*}{$\begin{array}{l}\text { Ability to maintain/establish a } \\
\text { therapeutic alliance, } n=29\end{array}$} & \multirow{3}{*}{$18(62.0)$} & \multirow{3}{*}{$11(37.9)$} & More difficult, 13 (72.2) \\
\hline & & & $\begin{array}{l}\text { More difficult for new clients and no different for } \\
\text { current clients, } 2 \text { (11.1) }\end{array}$ \\
\hline & & & More supportive, 3 (16.7) \\
\hline Ability to manage transference, $n=29$ & $10(34.4)$ & $19(65.5)$ & $\begin{array}{l}\text { More difficult to interpret client's emotional state, } 5 \\
(50.0)\end{array}$ \\
\hline $\begin{array}{l}\text { Ability to manage counter-transference, } \\
\mathrm{n}=29\end{array}$ & $9(31.0)$ & $20(68.9)$ & $\begin{array}{l}\text { More difficult to manage when working from home, } 6 \\
(66.7)\end{array}$ \\
\hline \multirow[t]{2}{*}{$\begin{array}{l}\text { Ability to feel and express empathy, } \\
n=28\end{array}$} & \multirow[t]{2}{*}{$10(35.7)$} & \multirow[t]{2}{*}{$18(64.2)$} & $\begin{array}{l}\text { More difficult, } 8(80.0) \text { Mostly due to limited } \\
\text { non-verbal communication and fatigue with screen } \\
\text { time }\end{array}$ \\
\hline & & & Requires more effort to convey empathy, 2 (20.0) \\
\hline $\begin{array}{l}\text { Capacity to conduct comprehensive risk } \\
\text { assessments as needed, } n=29\end{array}$ & $9(31.0)$ & $20(68.9)$ & $\begin{array}{l}\text { More difficult; feel less confident doing this via } \\
\text { telehealth, } 4(44.4)\end{array}$ \\
\hline Ability to manage risk, $n=28$ & $10(35.7)$ & $18(64.2)$ & $\begin{array}{l}\text { More difficult; client has access to means of self-injury; } \\
\text { harder to 'read' the situation, } 4(40.0)\end{array}$ \\
\hline $\begin{array}{l}\text { Time needed to develop a treatment } \\
\text { plan and/or crisis plan, } n=28\end{array}$ & $11(39.2)$ & $17(60.7)$ & $\begin{array}{l}\text { Longer; more time needed to establish rapport and } \\
\text { complete forms, } 5(45.5)\end{array}$ \\
\hline $\begin{array}{l}\text { Readiness of clients to practice their } \\
\text { skills between sessions, } n=28\end{array}$ & $6(21.4)$ & $22(78.5)$ & $\begin{array}{l}\text { Less ready; clients less motivated to practice skills, } 4 \\
(66.7)\end{array}$ \\
\hline \multirow{6}{*}{$\begin{array}{l}\text { Impact of any additional } \\
\text { (pandemic-related) stress being } \\
\text { experienced by clients, } \mathrm{n}=28\end{array}$} & \multirow{6}{*}{$23(82.1)$} & \multirow{6}{*}{$5(17.8)$} & Isolation, 5 (21.7) \\
\hline & & & Unemployment, 3 (13.0) \\
\hline & & & Anxiety/stress, 9 (39.1) \\
\hline & & & Psychosocial impact, 5 (21.7) \\
\hline & & & Reduced service access, 3 (13.0) \\
\hline & & & Suicidality; loss of agency, 2 (8.7) \\
\hline $\begin{array}{l}\text { Evidence for deterioration in clients' } \\
\text { financial situation (housing insecurity, } \\
\text { inability to pay bills/rent, loss of } \\
\text { income) }, n=29\end{array}$ & $13(44.8)$ & $16(55.1)$ & $\begin{array}{l}\text { Loss or decreased income; housing insecurity, } 6 \text { (46.2) } \\
\text { Increased income; government subsidy, } 2 \text { (15.4) }\end{array}$ \\
\hline $\begin{array}{l}\text { Evidence for deterioration in } \\
\text { relationships that is suggestive of } \\
\text { domestic violence, } n=29\end{array}$ & $8(27.5)$ & $21(72.4)$ & Presence or increase in domestic violence, 3 (37.5) \\
\hline Evidence for deterioration more & $14(50.0)$ & $14(50.0)$ & Increased tension with family members, 7 (50.0) \\
\hline
\end{tabular}


generally in interpersonal relationships with family and friends, $\mathrm{n}=28$

Challenges to the privacy and confidentiality of treatment sessions for the client, $\mathrm{n}=29$
Loss of contact or quality of contact with friends, 8 (57.1)

Some clients unable to find a suitable space, 8 (36.4)

Concerns for client's privacy and safety, 9 (40.9)

Have been there challenges to the privacy and confidentiality of treatment $17(58.6) \quad 12(41.3)$ sessions for you, the clinician? , $\mathrm{n}=29$ Lack of suitability of shared space, 2 (11.8)

$7(24.1)$

Need to adapt home office, 8 (47.1)

Privacy violated by client, 3 (17.6)

\subsection{Benefits and Shortcomings of Using Telehealth}

Positive aspects of using telehealth included ease of attending appointments which was reflected in a higher attendance rate (Table 4). More than half of participants (55.2\%) reported that clients were more likely to attend telehealth appointments.

'It's greatly convenient for the clients and it overcomes some socio-economic access issues re the cost of petrol or public transport. Some clients are highly anxious and require assistance with transport to and from sessions and this is no longer a barrier to engagement when they can telehealth a session instead. 'P25

Table 4. Positive and negative aspects of using telehealth to provide support and treatment for clients with personality disorder: clinician perspective $(\mathrm{n}=29)$

\begin{tabular}{|c|c|}
\hline Positive aspects of using telehealth & $\mathrm{n}(\%)$ \\
\hline Eliminates travel time and cost & $11(37.9)$ \\
\hline Access to treatment and support when other options are lacking & $9(31.0)$ \\
\hline Low drop out and higher attendance rate & $13(44.8)$ \\
\hline Reduced avoidance of social contact; agoraphobia & $6(20.6)$ \\
\hline $\begin{array}{l}\text { Clients feel more comfortable in home environment; better able to cope with vulnerability; exposure therapy able } \\
\text { to be done in the home }\end{array}$ & $4(13.7)$ \\
\hline $\begin{array}{l}\text { Increased efficiency; beneficial for secondary consultations (involving multiple healthcare professionals), more } \\
\text { flexibility to attend and engage }\end{array}$ & $5(17.2)$ \\
\hline Telehealth format facilitates some types of therapeutic exchanges & $3(10.3)$ \\
\hline More flexibility booking sessions at mutually convenient times & $2(6.8)$ \\
\hline \multicolumn{2}{|l|}{ Negative aspects of using telehealth } \\
\hline More challenging for clients; equipment needed for telehealth; client prefers in-person sessions & $3(10.3)$ \\
\hline Confidentiality, potential for boundary violations & $3(10.3)$ \\
\hline Does not address avoidance behaviours & $6(20.6)$ \\
\hline Inhibited interaction, 'passivity' & $9(31.0)$ \\
\hline Challenge ensuring that space is private and safe & $9(31.0)$ \\
\hline Lack of transition before and after session (travel, 'wind down') & $7(24.1)$ \\
\hline Inability to detect non-verbal cues and body language & $14(48.2)$ \\
\hline Internet interruptions very problematic & $10(34.4)$ \\
\hline Lack of connection, 'feeling' in the room, group dynamic & $11(37.9)$ \\
\hline Inability to assist fully with emotion dysregulation or crisis & $8(27.5)$ \\
\hline Sense of 'checking in' rather than therapeutic engagement & $11(37.9)$ \\
\hline Client can hang up; ambiguity (internet or deliberate) & $2(6.9)$ \\
\hline Sharing handouts, using whiteboard, evaluation measures more difficult & $3(10.3)$ \\
\hline
\end{tabular}


Some benefits experienced by clients were specifically noted by participants.

'They don't have to travel so far to attend. Some clients feel more comfortable being in their home environment and are more able to relax. Able to complete exposure in vivo in the environment in which the task is assigned.' P22

Participants' concerns clustered around their difficulty detecting non-verbal cues which diminished their sense of 'connection' and heightened the risk of misunderstandings. Technology glitches were also problematic, reducing their ability to fully engage and progress the therapeutic discussion.

'Not as containing an environment as being face-to-face in one room. Particularly if there are high levels of emotion. More difficult to challenge the client as concerned that I would be unable to adequately read the client's reaction. Concerns over the client's risk increasing during the session: again how to read the situation adequately without seeing body language.' P19

Participants reported fatigue and difficulty concentrating when interacting via a screen and/or phone: always ( $\mathrm{n}=5$, $17.2 \%)$, usually $(\mathrm{n}=10,34.4 \%)$, sometimes $(\mathrm{n}=11,37.9 \%)$ and rarely $(\mathrm{n}=3,10.3 \%)$. There was a stated need for boundaries specific to telehealth sessions to contain unhelpful and risky behaviours. These included establishing private and safe spaces, confidentiality agreements, and behavioural limits (e.g. no smoking or lying in bed; Table $3)$.

'A client having her partner present in the background of groups [was] a violation of other group members' privacy' $\mathrm{P} 18$

\subsection{Future Use of Telehealth}

Twelve clinicians provided suggestions for optimising future use of telehealth. These included improving space and equipment at the workplace, development of guidelines (particularly relating to managing risk and trauma content), employer advocating for staff after privacy breaches, and improving national broadband services.

Nearly all participants saw value in telehealth for completing non-clinical work such as meetings and administrative tasks. In terms of participant willingness to use telehealth to deliver psychotherapy after returning to work, many were willing $(58.6 \%)$, some were unsure $(34.5 \%)$ or preferred not to $(6.9 \%)$.

'Would like the opportunity to be able to work from home at times, especially if not completing face-to-face sessions.'P18

'Would like the opportunity to be able to complete telehealth sessions if requested by client and clinically indicated (though would not like to be forced into using this medium). 'P9

With regard to their clients' preference for in-person versus telehealth services, participants thought many of their clients would prefer to return to in-person treatment $(55.2 \%)$, with most wanting to continue with or retain the option of using telehealth (65.5\%).

I believe the majority of clients want to return to face-to-face when they can. Some clients have talked about preferring telehealth though they have suggested that this may relate to anxiety about coming in to face-to-face sessions and they acknowledge that they want to work on this anxiety. Clients particularly have found groups harder.'P32

\subsection{Informal Clinician Feedback Eight Months after the Survey}

Follow-up with clinicians was conducted after eight months of providing psychotherapy via telehealth. Although technical difficulties were resolved or being managed, a range of psychotherapy and telehealth-specific concerns had emerged, including difficulties with accurate risk assessment, duty of care in the event that a client left a session in distress, privacy breaches, a gradual loss of engagement with clients over time, client preference for telehealth when masks and face shields were compulsory for in-person sessions, difficulty of using telehealth in the absence of establishing an in-person foundation, the contribution of telehealth to avoidance issues, lack of staff training regarding legal issues associated with treatment via telehealth, and a clear need for a formal agreement process with clients prior to engaging in telehealth treatment.

\section{Discussion}

Prior to the COVID-19 restrictions, telehealth accounted for a small proportion of the service's work, used mainly for secondary consultation or professional supervision. Most clinicians expressed prior doubts about telehealth delivery of specialized psychotherapy to clients suffering from severe personality disorder, with concerns about how telehealth might negatively impact the therapeutic alliance (Lopez et al., 2019; Norwood, Moghaddam, Malins, \& Sabin-Farrell, 2018; Richter et al., 2020); security, privacy and confidentiality of telehealth platforms for clinicians and clients (Gordon, Wang, \& Tune, 2018; Van Daele et al., 2020); difficulty gauging risk to client or 
others (Jobes, Crumlish, \& Evans, 2020); and doubts about the overall efficacy of psychotherapy delivered via telehealth (Irvine et al., 2020).

The rapidly changing circumstances associated with COVID-19 meant that there was little prior warning before moving treatment services to telehealth (D'Agostino, Demartini, Cavallotti, \& Gambini, 2020; Richter et al., 2020; Tullio, Perrone, Bilotta, Lanzarone, \& Argo, 2020). The transition relied on staff having their own equipment and internet service, which initially presented significant problems for staff and clients (Lakeman \& Crighton, 2020). However, initial technical problems were mostly addressed due to the setting - a large metropolitan center in a high-income country - in contrast to countries and regional areas lacking infrastructure and means (Lakeman \& Crighton, 2020; Satalkar, Shrivastava, \& De Sousa, 2015; Summers-Gabr, 2020). Continuing this important work in a very vulnerable client group was critical, particularly given the mental health consequences associated with extended social isolation (Hossain, Sultana, \& Purohit, 2020; Hoyer et al., 2020; Mian, Al-Asad, \& Khan, 2020; Tullio et al., 2020).

The present study highlighted some benefits of telehealth, substantially improving treatment attendance by reducing barriers such as travel time and social anxiety. Several participants were concerned that client difficulties with avoidance and anxiety might not be addressed effectively via telehealth, underscoring the need to ascertain the suitability of telehealth for individual client needs once the restrictions ease (Pierce et al., 2020; Sasangohar et al., 2020).

The quality of therapeutic engagement was variably affected by telehealth delivery. Some cited a 'lack of connection', a sense of 'just checking in', and generally inhibited interaction (Norwood et al., 2018), while others felt their clients were less inhibited about discussing difficult topics while in their home environment (Chen et al., 2020; Kocsis \& Yellowlees, 2018). Some adjusted treatment sessions for telehealth delivery, making them shorter, more frequent, and incorporating a 'transition' step to replace the 'wind down' that generally occurs when clients travel home.

Increased suicidality has been reported in a large US-based study (Czeisler et al., 2020); chronic suicidality is a distinguishing feature of BPD (Broadbear et al., 2020). An important consideration when treating someone with BPD is assessing their risk of self-harm and suicidality (Rao et al., 2017). Although no serious adverse outcomes were reported during the eight months covered by this study, it was clear that clinicians (and likely their clients) had difficulty perceiving non-verbal cues during sessions. Nuances of expression, changes in body posture, and expressive gestures may not be communicated via screens or phones (Fisher, Guralnik, Fonagy, \& Zilcha-Mano, 2020), increasing the likelihood of miscommunication and ruptures. The ambiguity of a disrupted internet connection (an impulsive action of a distressed client or an internet glitch) raised questions about safety, duty of care, and legal responsibility for instituting a welfare check. Similarly, a threat of self-harm or suicide requires a programmed response that addresses acute risk and alleviates clinician anxiety. Some guidance is available (Hames et al., 2020; Jobes et al., 2020; Smith, Ostinelli, Macdonald, \& Cipriani, 2020); however, services that are still formulating their policies run the risk of having clinicians feel isolated and unsupported.

The high incidence of trauma in people diagnosed with BPD heightens the likelihood that distressing content will be disclosed during psychotherapy sessions. Telehealth reduces clinicians' ability to empathize and comfort clients. If not addressed, these limitations could undermine the development and maintenance of therapeutic relationships and impede the adoption of telehealth treatment services (Irvine et al., 2020). Despite these significant concerns, many clinicians felt their relationship with clients was unhindered by telehealth which accords with previous reports (Irvine et al., 2020; Norwood et al., 2018; Watts et al., 2020). Informal feedback provided eight months after the survey was conducted concluded on balance that while telehealth was preferred by some clients, specifically when mask and face shields were mandatory when meeting in person, the inadequacies of the exclusive use of telehealth were clear. Clinicians were concerned about accurate risk assessment, duty of care in ambiguous or risky situations, a gradual loss of engagement with clients over time, and the lack of staff training regarding legal issues associated with delivering treatment via telehealth.

\subsection{Limitations}

This study was designed to capture the experiences of clinicians during the first wave of COVID-19 lockdown. The cross-sectional survey design was helpful in capturing a 'fleeting' moment during the early stages of the pandemic but is limited in terms of capturing the changes in telehealth perceptions that emerged during subsequent waves of infection and lockdown. While the survey participants were followed up informally eight months later, this approach lacked the scientific rigor needed to draw firm conclusions. 


\section{Conclusions}

Once restrictions ease, we must decide how best to incorporate telehealth into psychotherapeutic work (Sasangohar et al., 2020; Smith et al., 2020; Wind, Rijkeboer, Andersson, \& Riper, 2020). Telehealth has now gained substantial acceptance among clinicians and clients and will likely play a greater ongoing role within the mental health system. This study suggests some utility for delivering evidence-based psychotherapy via telehealth platforms; however, clinical imperatives and client preferences will be important determinants in how telehealth is used, alongside the development and promulgation of telehealth guidance and regulation. Although the effectiveness of telehealth has been demonstrated for other serious mental health conditions (Berryhill et al., 2019; Markowitz et al., 2020; Miu, Vo, Palka, Glowacki, \& Robinson, 2020), there are no equivalent studies for personality disorders. Future studies will determine the relative efficacy of telehealth and in-person sessions for the treatment of severe personality disorder.

\section{Competing Interests Statement}

The authors declare that there are no competing or potential conflicts of interest.

\section{References}

Berryhill, M. B., Culmer, N., Williams, N., Halli-Tierney, A., Betancourt, A., Roberts, H., \& King, M. (2019). Videoconferencing psychotherapy and depression: a systematic review. Telemedicine and e-Health, 25(6), 435-446. https://doi.org/10.1089/tmj.2018.0058

Broadbear, J. H., Dwyer, J., Bugeja, L., \& Rao, S. (2020). Coroners' investigations of suicide in Australia: The hidden toll of borderline personality disorder. Journal of Psychiatric Research, 129, 241-249. https://doi.org/10.1016/j.jpsychires.2020.07.007

Budge, S. L., Moore, J. T., Del Re, A., Wampold, B. E., Baardseth, T. P., \& Nienhuis, J. B. (2013). The effectiveness of evidence-based treatments for personality disorders when comparing treatment-as-usual and bona fide treatments. Clinical Psychology Review, 33(8), 1057-1066. https://doi.org/10.1016/j.cpr.2013.08.003

Chen, C. K., Nehrig, N., Wash, L., Schneider, J. A., Ashkenazi, S., Cairo, E., . . Palfrey, A. (2020). When distance brings us closer: leveraging tele-psychotherapy to build deeper connection. Counselling Psychology Quarterly, 1-14. https://doi.org/10.1080/09515070.2020.1779031

Czeisler, M. É., Lane, R. I., Petrosky, E., Wiley, J. F., Christensen, A., Njai, R., . . Barger, L. K. (2020). Mental health, substance use, and suicidal ideation during the COVID-19 pandemic-United States, June 24-30, 2020. Morbidity and Mortality Weekly Report, 69(32), 1049. https://doi.org/10.15585/mmwr.mm6932a1

D'Agostino, A., Demartini, B., Cavallotti, S., \& Gambini, O. (2020). Mental health services in Italy during the COVID-19 outbreak. The Lancet Psychiatry, 7(5), 385-387. https://doi.org/10.1016/S2215-0366(20)30133-4

Dharwadkar, N. P., Broadbear, J. H., Heidari, P., Cheney, L., \& Rao, S. (2021). Psychotherapy via telehealth during the COVID-19 pandemic - an Australian consumer experience (Under review).

Elo, S., \& Kyngäs, H. (2008). The qualitative content analysis process. Journal of Advanced Nursing, 62(1), 107-115. https://doi.org/10.1111/j.1365-2648.2007.04569.x

Fife, W. (2020). Counting as a Qualitative Method. Springer. https://doi.org/10.1007/978-3-030-34803-8

Fisher, S., Guralnik, T., Fonagy, P., \& Zilcha-Mano, S. (2020). Let's face it: video conferencing psychotherapy requires the extensive use of ostensive cues. Counselling Psychology Quarterly, 1-17. https://doi.org/10.1080/09515070.2020.1777535

Gordon, R. M., Wang, X., \& Tune, J. (2018). Research on teaching, supervision and psychotherapy using video conference technology. In Psychoanalysis Online 4 (pp. 126-138): Routledge. https://doi.org/10.4324/9780429458248-13

Government response to the COVID-19 outbreak. (2020).

Grubaugh, A. L., Cain, G. D., Elhai, J. D., Patrick, S. L., \& Frueh, B. C. (2008). Attitudes toward medical and mental health care delivered via telehealth applications among rural and urban primary care patients. The Journal of Nervous and Mental Disease, 196(2), 166-170. https://doi.org/10.1097/NMD.0b013e318162aa2d

Hames, J. L., Bell, D. J., Perez-Lima, L. M., Holm-Denoma, J. M., Rooney, T., Charles, N. E., . . Fondacaro, K. M. (2020). Navigating uncharted waters: Considerations for training clinics in the rapid transition to telepsychology and telesupervision during COVID-19. Journal of Psychotherapy Integration, 30(2), 348. 
https://doi.org/10.1037/int0000224

Hossain, M. M., Sultana, A., \& Purohit, N. (2020). Mental health outcomes of quarantine and isolation for infection prevention: A systematic umbrella review of the global evidence. Available at SSRN 3561265. https://doi.org/10.21203/rs.3.rs-25647/v1

Hoyer, C., Ebert, A., Szabo, K., Platten, M., Meyer-Lindenberg, A., \& Kranaster, L. (2020). Decreased utilization of mental health emergency services during the COVID-19 pandemic. European Archives of Psychiatry and Clinical Neuroscience, 1. https://doi.org/10.1007/s00406-020-01151-w

Huang, Y., Kotov, R., De Girolamo, G., Preti, A., Angermeyer, M., Benjet, C., . . Karam, A. N. (2009). DSM-IV personality disorders in the WHO World Mental Health Surveys. The British Journal of Psychiatry, 195(1), 46-53. https://doi.org/10.1192/bjp.bp.108.058552

Irvine, A., Drew, P., Bower, P., Brooks, H., Gellatly, J., Armitage, C. J., . . B Bee, P. (2020). Are there interactional differences between telephone and face-to-face psychological therapy? A systematic review of comparative studies. Journal of Affective Disorders, 265, 120-131. https://doi.org/10.1016/j.jad.2020.01.057

Jobes, D. A., Crumlish, J. A., \& Evans, A. D. (2020). The COVID-19 pandemic and treating suicidal risk: The telepsychotherapy use of CAMS. Journal of Psychotherapy Integration, 30(2), 226. https://doi.org/10.1037/int0000208

Kocsis, B. J., \& Yellowlees, P. (2018). Telepsychotherapy and the therapeutic relationship: Principles, advantages, and case examples. Telemedicine and e-Health, 24(5), 329-334. https://doi.org/10.1089/tmj.2017.0088

Lakeman, R., \& Crighton, J. (2020). The Impact of Social Distancing on People with Borderline Personality Disorder: The Views of Dialectical Behavioural Therapists. Issues in Mental Health Nursing, 1-7. https://doi.org/10.1080/01612840.2020.1817208

Leichsenring, F., Leibing, E., Kruse, J., New, A. S., \& Leweke, F. (2011). Borderline personality disorder. The Lancet, 377(9759), 74-84. https://doi.org/10.1016/S0140-6736(10)61422-5

Looi, J. C., \& Pring, W. (2020). Private metropolitan telepsychiatry in Australia during Covid-19: current practice and future developments. Australasian 1039856220930675. https://doi.org/10.1177/1039856220930675

Lopez, A., Schwenk, S., Schneck, C. D., Griffin, R. J., \& Mishkind, M. C. (2019). Technology-based mental health treatment and the impact on the therapeutic alliance. Current Psychiatry Reports, $21(8), 76$. https://doi.org/10.1007/s11920-019-1055-7

Luo, C., Sanger, N., Singhal, N., Pattrick, K., Shams, I., Shahid, H., . . . Haber, S. (2020). A comparison of electronically-delivered and face to face cognitive behavioural therapies in depressive disorders: A systematic review and meta-analysis. EClinicalMedicine, 24, 100442. https://doi.org/10.1016/j.eclinm.2020.100442

Markowitz, J. C., Milrod, B., Heckman, T. G., Bergman, M., Amsalem, D., Zalman, H., . . Neria, Y. (2020). Psychotherapy at a Distance. American Journal of Psychiatry, appi. ajp. 2020.20050557. https://doi.org/10.1176/appi.ajp.2020.20050557

Mian, A., Al-Asad, S., \& Khan, S. (2020). Mental health burden of COVID-19. Family Practice. https://doi.org/10.1093/fampra/cmaa100

Miu, A. S., Vo, H. T., Palka, J. M., Glowacki, C. R., \& Robinson, R. J. (2020). Teletherapy with serious mental illness populations during COVID-19: telehealth conversion and engagement. Counselling Psychology Quarterly, 1-18. https://doi.org/10.1080/09515070.2020.1791800

Mohr, D. C., Vella, L., Hart, S., Heckman, T., \& Simon, G. (2008). The effect of telephone-administered psychotherapy on symptoms of depression and attrition: A meta-analysis. Clinical Psychology: Science and Practice, 15(3), 243-253. https://doi.org/10.1111/j.1468-2850.2008.00134.x

Norwood, C., Moghaddam, N. G., Malins, S., \& Sabin-Farrell, R. (2018). Working alliance and outcome effectiveness in video-conferencing psychotherapy: A systematic review and noninferiority meta-analysis. Clinical Psychology \& Psychotherapy, 25(6), 797-808. https://doi.org/10.1002/cpp.2315

Osenbach, J. E., O'Brien, K. M., Mishkind, M., \& Smolenski, D. J. (2013). Synchronous telehealth technologies in psychotherapy for depression: A meta-analysis. Depression and Anxiety, 30(11), 1058-1067. https://doi.org/10.1002/da.22165

Perle, J. G., \& Nierenberg, B. (2013). How psychological telehealth can alleviate society's mental health burden: A 
literature review. Journal of Technology in Human Services, 31(1), $22-41$. https://doi.org/10.1080/15228835.2012.760332

Pierce, B. S., Perrin, P. B., Tyler, C. M., McKee, G. B., \& Watson, J. D. (2020). The COVID-19 telepsychology revolution: A national study of pandemic-based changes in US mental health care delivery. American Psychologist. https://doi.org/10.1037/amp0000722

Rao, S., Broadbear, J. H., Thompson, K., Correia, A., Preston, M., Katz, P., \& Trett, R. (2017). Evaluation of a novel risk assessment method for self-harm associated with Borderline Personality Disorder. Australasian Psychiatry, 25(5), 460-465. https://doi.org/10.1177/1039856217707390

Richter, D., Bonsack, C., Burr, C., Gekle, W., Hepp, U., Kawohl, W., . . Jäger, M. (2020). Therapeutic alliance, social inclusion and infection control-Towards pandemic-adapted mental health care services in Switzerland. Swiss Archives of Neurology, Psychiatry and Psychotherapy, Epub ahead of print. https://doi.org/10.31234/osf.io/bs3ej

Sasangohar, F., Bradshaw, M. R., Carlson, M. M., Flack, J. N., Fowler, J. C., Freeland, D., .. . Weinstein, B. (2020). Adapting an Outpatient Psychiatric Clinic to Telehealth During the COVID-19 Pandemic: A Practice Perspective. Journal of Medical Internet Research, 22(10), e22523. https://doi.org/10.2196/22523

Satalkar, P., Shrivastava, S., \& De Sousa, A. (2015). Internet-mediated psychotherapy: Are we ready for the ethical challenges. Indian Journal of Medical Ethics, 12(4), 220-227. https://doi.org/10.20529/IJME.2015.058

Smith, K., Ostinelli, E., Macdonald, O., \& Cipriani, A. (2020). COVID-19 and Telepsychiatry: development of evidence-based guidance for clinicians. JMIR mental health, 7(8), e21108. https://doi.org/10.2196/21108

Summers-Gabr, N. M. (2020). Rural-urban mental health disparities in the United States during COVID-19. Psychological Trauma: Theory, Research, Practice, and Policy. https://doi.org/10.1037/tra0000871

Tullio, V., Perrone, G., Bilotta, C., Lanzarone, A., \& Argo, A. (2020). Psychological support and psychotherapy via digital devices in Covid-19 emergency time: Some critical issues. Medico-Legal Journal, 0025817220926942. https://doi.org/10.1177/0025817220926942

Van Daele, T., Karekla, M., Kassianos, A. P., Compare, A., Haddouk, L., Salgado, J., .. . Van Assche, E. (2020). Recommendations for policy and practice of telepsychotherapy and e-mental health in Europe and beyond. Journal of Psychotherapy Integration, 30(2), 160. https://doi.org/10.1037/int0000218

Watts, S., Marchand, A., Bouchard, S., Gosselin, P., Langlois, F., Belleville, G., \& Dugas, M. J. (2020). Telepsychotherapy for generalized anxiety disorder: Impact on the working alliance. Journal of Psychotherapy Integration, 30(2), 208. https://doi.org/10.1037/int0000223

Wind, T. R., Rijkeboer, M., Andersson, G., \& Riper, H. (2020). The COVID-19 pandemic: The 'black swan'for mental health care and a turning point for e-health. Internet interventions, 20. https://doi.org/10.1016/j.invent.2020.100317

World Health Organisation [WHO]. (2020). Telehealth. Global Health Observatory (GHO) data. Retrieved from https://www.who.int/gho/goe/telehealth/en/

\section{Copyrights}

Copyright for this article is retained by the author(s), with first publication rights granted to the journal.

This is an open-access article distributed under the terms and conditions of the Creative Commons Attribution license (http://creativecommons.org/licenses/by/4.0/). 